ARTIGO

Recebido em:

01/04/2013

Aceito em:

09/04/2013

\title{
A macro-level study of science in Brazil: seven years later
}

\author{
Jacqueline LETA ${ }^{1}$ \\ Bart THIJS 2 \\ Wolfgang GLÄNZEL ${ }^{3}$
}

\begin{abstract}
Following earlier studies by the authors published in 2006, the evolution of publication activity and citation impact in Brazil is studied for more recent years up to 2011. Similarly to these studies, an analysis of publication and citation patterns and of national publication profiles is conducted to make it possible to compare recent trends with patterns found earlier. An attempt is made to find also statistical evidences of the relation between international co-authorship and both research profile and citation impact in the Latin American region. The authors compare their results with finding from other bibliometric studies of BRICS and N-11 countries. The enormous growth of Brazilian publication output forms the largest potential reaching far beyond the Latin American world region.
\end{abstract}

KEYWORDS: Brazilian Science. Scientometrics. Citations. Publications.

\section{INTRODUCTION}

In 2006, two extensive studies devoted to Brazilian science in the period of 1991-2003 were published by our group, one with a regional approach (Glänzel et al., 2006) and the other one with a local approach (Leta et al., 2006).

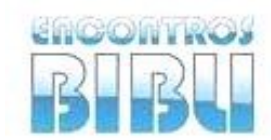

v. 18, n. $36,2013$. p. $51-66$

ISSN 1518-2924
${ }^{1}$ Federal University of Rio de Janeiro - jleta@bioqmed.ufri.br

${ }^{2}$ Centre for R\&D Monitoring (ECOOM) and Dept. MSI, KU Leuven, Leuven, Belgium Bart.Thijs@econ.kuleuven.be

${ }^{3}$ Centre for R\&D Monitoring (ECOOM) and Dept. MSI, KU Leuven, Leuven, Belgium - Dept. Science Policy \& Scientometrics, LHAS, Budapest, Hungary Wolfgang.Glanzel@econ.kuleuven.ac.be 
Regarding the first paper, we presented evidence of Brazilian publication activity and its citation impact within the context of the most prolific Latin American countries (Argentina, Chile, Mexico and Venezuela). We showed that among these countries, Brazilian publication output formed the largest one, with an annual growth rate of about 8\%. By arranging publications into 12 major fields (Glänzel and Schubert, 2003), we found that all of the five countries did follow the model III which stands for a paradigmatic pattern of publications (REIST-2, 1997), where biology, agriculture and earth \& space sciences are in the focus. Among this set of countries, Brazil represented a better-balanced performance in terms of the relative weight of the scientific output in each of the twelve fields according to the Leuven-Budapest classification scheme (Glänzel and Schubert, 2003). As for citation impact, we found a lower performance in most of the fields for all countries but surprisingly we found that publications from medicine and engineering attracted relatively more citations in some of the countries. The paper also presented statistical evidences of the relation between international co-authorship in the region. We found that, with the exception of Brazil, the share of scientific publications with international co-authors increased significantly in the other four countries. While some of the countries displayed shares of international co-authorship around 50\%, Brazil showed a steady share, around 35\%. Another important feature we found, with respect to the Brazilian international co-operation patterns: the number of links as well as the number of strong links among Brazil and other countries increased remarkably from the 1991-1995 to the 19992003, especially those links established among Brazil and other Latin American countries.

For the comparison of the developments in the six selected countries of the region with the evolution of publication output and profiles, of international collaboration and citation impact of other countries in Latin America and the Caribbean in the 1990's and the new millennium, the reader might refer to a more recent study by Schlemmer and Glänzel (2008).

Our previous results pointed to the strategic role of Brazil for the development of science in the region, a key aspect to the social and economic 
improvement of the whole region. In recent years, however, the participation of Brazilian science in mainstream databases has increased even more, taking the country to raise some positions in the world's ranking of publications (Regalado, 2010; Leta, 2011). Such increase seems to be a result of a combination of some internal and external factors, including the continuous investment of the public sector in qualifying human resources and improving infrastructure as well as the inclusion of dozens of new Brazilian titles in major scientific databases (Leta, 2011).

Despite the reasons behind this recent growth, the fact is that a larger number of Brazilian publications have now international visibility and audience. Considering the recent and impressive growth of Brazilian publications, we questioned, "did it reflect in changes on the country's performance in terms of its share in the world and Latin America?" Bearing in mind this research question, we elaborated the present paper where we compare some recent data - from 2007 to 2011 - to those we have processed in one of our previous paper (Glänzel et al., 2006). We believe such data updating may allow us to better understanding whether or not the increase of Brazilian journals indexed in the main international databases, resulted in changes in the country's and region's performance.

According to a study of "global changes in a dynamic world" (Glänzel et al., 2009), it has been shown that Brazil, jointly with South Korea, Taiwan, and Turkey, evolved to the most dynamically growing scientific nations already in the period 1991-2005, and that these emerging scientific nations together with other BRICS and N-11 countries like China, Russia and India are already changing the global balance of power as measured by scientific production.

\section{METHODOLOGY}

The bibliographic data used in this study were extracted from the 19912011 annual volumes of Thomson Reuters' Web of Science (WoS) available for use at the Katholieke Universiteit Leuven (Belgium). Only document types named as articles, letters, notes, proceedings papers and reviews were considered 
for analysis. Publications were assigned to countries based on their corporate addresses, which appear in the by-line of each publication.

As for subject classification, publications were arranged into twelve major fields: Agriculture \& Environment, Biology (Organism \& Supraorganismic level), Biosciences (General, Cellular \& Subcellular Biology, Genetics), Biomedical research, Clinical \& Experimental Medicine I (General \& Internal Medicine), Clinical \& Experimental Medicine II (Non-Internal Medicine Specialties), Neuroscience \& Behaviour, Chemistry, Physics, Geosciences \& Space Sciences, Engineering and, finally, Mathematics. Glänzel \& Schubert (2003) developed this classification scheme based on the field assignment of journals.

For the citation analysis, a three-year citation window was applied for all papers published in 1991-2009. Citations received by these publications were determined as the sum of citations received in the publication year and the citations received during the subsequent two years. Author self-citations were not excluded in this study.

Publication profiles were determined using the Activity Index (AI) indicator originally introduced to scientometrics by Frame (1977), by the way, in a study of research in Latin America. AI is defined as the ratio of the share of a given field in the publications of a given country to the share of the same field in the world total publications. It is easy to see that AI reflects an internal balance situation. Its neutral value is 1 (country's performance is similar to the world's reference standard in the given field); $\mathrm{AI}=0$ indicates a completely idle research field, AI $<0$ indicates the country has a lower-than-average performance while $\mathrm{AI}>1$ a higher-than average activity. It is obvious that a country's AI values cannot be less or greater than 1 in all fields. As a "fictitious" example: in 1970, Brazil had 150 publications, including 15 publications in the field of Chemistry; in the same year, the world (i.e., the whole database) published 20,000 publications and 4,000 were assigned to Chemistry. The equation for this example is $\mathrm{AI}=(15 / 150) /(4,000 / 20,000)$ resulting in $\mathrm{AI}=$ 0.5. This means that Brazilian relative activity in Chemistry in 1970 was half of the world's standard. 
The analysis of citation performance is based on the Relative Citation Rate (RCR) indicator, which is defined as the ratio of two other citation-impact measures, the Mean Observed Citation Rate (MOCR) and the Mean Expected Citation Rate (MECR). MOCR is the ratio of citation and publication count (Braun et al., 1985), while (MECR) is a journal-based indicator, that is, it expresses the expected citation rate of a given paper set. The journal-based expected citation rate of a single paper is defined as the average citation rate of all papers published in the same journal, in the same year, in a three-year citation window. MECR is thus defined as the average of these individual expectations over a given paper set. Following the same rationality as stated previously, we have: RCR $=0$ corresponds to uncitedness, RCR $<1$ represents lower-than-theaverage, RCR > 1 represents higher-than-the-average and finally RCR = 1 means that the papers received the number of citations expected on the basis of the average citation rate of the publishing journals. The choice of journals as individual reference standard guarantees that RCR is to the greatest extent insensitive to the subject-specific biases of citation impact. Unlike the AI indicators RCR does not reflect any internal balance: A country's relative citation rate can indeed exceed the neutral value 1 in all fields, or, conversely, it can remain below the reference standard in all fields. Considering the same "fictitious" example, the 15 Brazilian papers received 50 citations in a threeyear citation window. Hence, MOCR (Brazil)=3.3. After counting (automatically) citations received by all papers published in journals where Brazilian publications were published (in the same three-year window), we found a fictitious MECR (Brazil)=5.2. The equation for this example is $\mathrm{RCR}=3.3 / 5.2$, $\mathrm{RCR}=0.6$, that means Brazilian papers are less cited than the world.

\section{BRAZIL AND THE MOST PROLIFIC COUNTRIES IN LATIN AMERICA}

Recently a study by Huggett (2012) showed that the number of scientific publications from Latin American countries indexed in Elsevier's SCOPUS database increased by more than annually 9\% in the period of 2000-2010. According to the author, such growth resulted "in a nearly $70 \%$ increase in its 
share of world papers over the same period, to reach just under $4.4 \%$ of the world's annual output of scholarly papers in 2010".

In our previous study (Glänzel et al., 2006), we had already pointed to some striking changes in the region's share in the global publication output. However, in contrast to Huggett, we investigated a different period, namely 1991-2003, and data were collected from the Web of Science.

In Table 1, we present the updated information only about the most prolific Latin American countries in terms of publication output as indexed in the WoS. In contrast to our previous study, we included Colombia since its share to the world total reached more than $0.1 \%$ in the period $2007-2011$.

\begin{tabular}{lccccccccc}
\hline & \multicolumn{3}{c}{$1991-1995$} & \multicolumn{3}{c}{$1999-2003$} & \multicolumn{2}{c}{$2007-2011$} \\
\cline { 2 - 6 } Country & Papers & Rank & Share & Papers & Rank & Share & Papers & Rank & Share \\
\hline Brazil & 24,039 & 23 & $0.71 \%$ & 59,767 & 17 & $1.46 \%$ & 147,503 & 13 & $2.59 \%$ \\
Argentina & 11,570 & 33 & $0.34 \%$ & 23,057 & 29 & $0.56 \%$ & 34,297 & 33 & $0.60 \%$ \\
Mexico & 11,329 & 34 & $0.34 \%$ & 26,704 & 27 & $0.65 \%$ & 44,987 & 28 & $0.79 \%$ \\
Chile & 6,330 & 45 & $0.19 \%$ & 10,864 & 39 & $0.27 \%$ & 21,327 & 43 & $0.37 \%$ \\
Venezuela & 3,033 & 50 & $0.09 \%$ & 5,239 & 50 & $0.13 \%$ & 6,021 & 57 & $0.11 \%$ \\
Colombia & 1,176 & 66 & $0.03 \%$ & 3,329 & 57 & $0.08 \%$ & 10,718 & 52 & $0.19 \%$ \\
\hline
\end{tabular}

Table 1: Number of publications, ranking and world share in publications of the top six countries in Latin American

[Data sourced from Thomson Reuters Web of Science] 

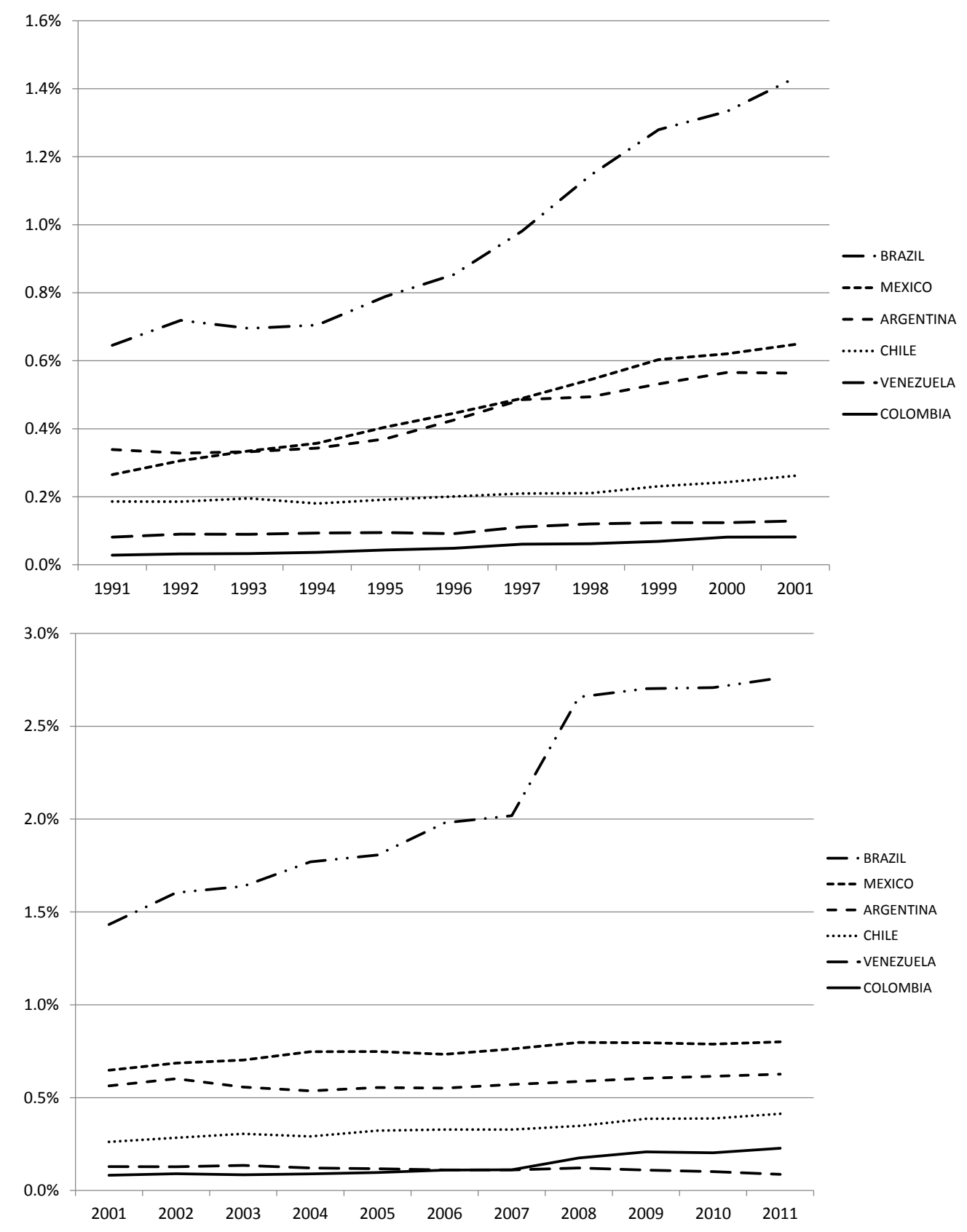

Figure 1: Share of publications in the world total of the most prolific Latin American countries, 1991-2001 (top) and 2001-2011 (bottom).

[Data sourced from Thomson Reuters Web of Science]

As one can note, all six countries included in our analysis increased their number of publications and their world share from the first to the last period. Nevertheless, this increase does not necessary represent a positive change in their position in the world's ranking. This is most evident for Venezuela and Argentina. 
Figure 1 shows the annual change of the six countries' world share in publication output split in to the two sub-periods 1991-2001 and 2001-2011. The leadership position of Brazil is quite obvious. This trend is clearly strengthened after 2007, i.e., the year where new Brazilian journals were covered in the WoS database. From then on, the Brazilian share increased vary fast, reaching more than $2 \%$ of the world's total publication output.

We note that the inclusion of new Brazilian source titles did not affect its neighbors' world share. In the more recent sub-period (bottom graph of Figure 1), Argentina and Venezuela seem to stagnate, while Mexico and Chile tend to rise their weight in the region.

Brazilian leadership among the six countries under study is beyond doubt. In the two decades, Brazil jumped from the $23^{\text {rd }}$ to the $13^{\text {th }}$ position according to national publication output in the world ranking. This impressive performance is the result of a combination of some factors, including the continuous investment of the public sector in qualifying human capitals and improving infrastructure in general, especially in public universities and research institutes, as well as the inclusion of dozens of new Brazilian journals in one of the largest multidisciplinary bibliographic databases. Regarding this last aspect, Leta (2011) found that the largest fraction of more recent publications is published in national journals, which were recently indexed by the two databases used in her study. Hence, the author discussed the role of national journals to diffuse the country's knowledge.

\section{PUBLICATION AND IMPACT: LATIN AMERICAN COUNTRIES PERFORMANCE OVER TIME}

It is well known that Latin American countries do differ in many cultural and social aspects but this divergence does not necessarily apply to scientific research, at least when their Activity Index values are compared. And taking into account the paradigmatic patterns for publication profiles established by REIST-2 (1997), in our previous study we concluded that model III prevailed among the selected Latin American countries in both periods 1991-1995 and 
1999-2003 (Glänzel et al., 2006). This model - with biology, agriculture and earth and space in the foreground - is also called 'bio-environmental model'. Despite some exceptions, the countries under study did not show high relative activity in the fields of biomedicine and clinical medicine (model I, also called the 'Western model'), in chemistry and physics (model II, which is typical of the former socialist countries) or in the fields of engineering and chemistry (model IV, which also called the 'Japanese model'). In the case of Brazil, the high activity of the country in physics is contrasted by clearly less high in chemistry, what militated for the interpretation of Brazil's profile as model III.

As for the most recent period, 2007-2011, we found no significant changes in terms of the general model, in other words, model III still prevails among the six countries. For most of the countries, we noted an increase in the relative share of the biology, agriculture and space sciences fields. We did not observe any remarkable (positive or negative) changes in the relative weight of other fields.

In the case of Brazil, both the relative increase in clinical medicine and the relative decrease in physics are worth mentioning. Such shifts can be the result of the recent incresing database coverage of Brazilian journals, which were mainly assigned to the fields of biology, biomedicine and clinical medicine. A larger number of journals indexed in the WoS in these fields means a higher share of publications to the country's total output, which, in turn, is one of the variables in the formula of AI. On the other hand, it might happen that all other fields reduced their shares and this apparently occurred clearer in physics. 

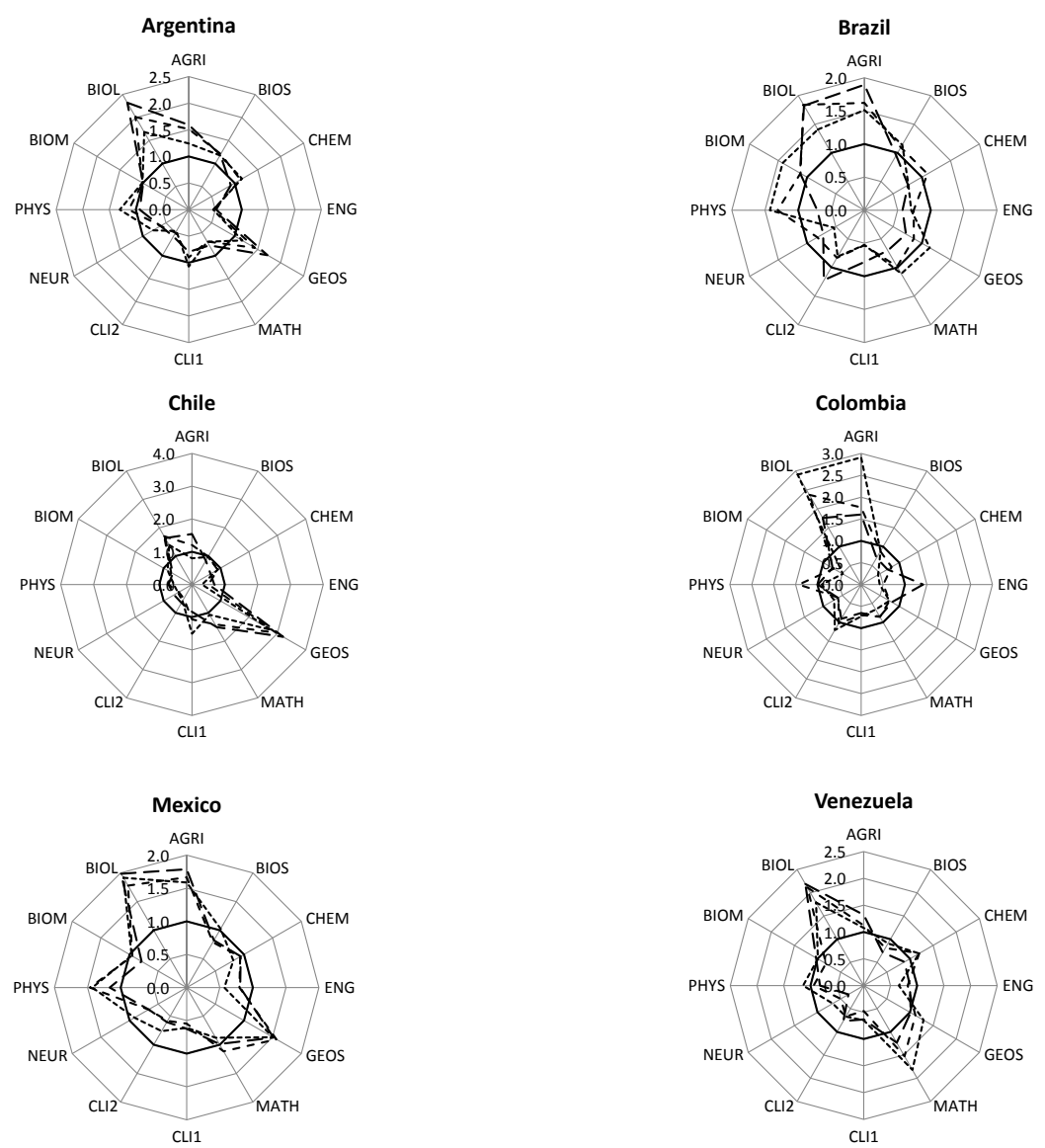

----1991-1995 - - -1999-2003 - -2007-2011 —Standard

Figure 2: Evolution of Activity Index (AI) of the most prolific Latin American countries.

[Data sourced from Thomson Reuters Web of Science]

Legend: AGR = Agriculture \& Environment, Biology, BIOS = Biosciences, BIOM = Biomedical research, CLI1 = Clinicl \& Experimental Medicine I, CLI2= Clinical \& Experimental Medicine II, NEUR= Neuroscience \& Behaviour, CHEM= Chemistry, PHYS= Physics, GEOS= Geosciences \& Space Sciences, $\mathrm{ENG}=$ Engineering, $\mathrm{MATH}=$ Mathematics

We have also analyzed the citation impact of the countries already selected in our previous study. At that time, we presented evidence that although the countries under study showed a better performance in biology, agriculture and space sciences, the actual values of the Relative Citation Rate (RCR) in these fields were lower than the world standard. In contrast, we found the highest RCR values in medicine and engineering, which are fields with the lowest relative weight in the two periods analyzed at that time.

For the present paper, we expanded this analysis by processing data on citation of publications published in one of the four periods: 1991-1995, 1997- 
2001, 2002-2005 and 2006-2011 (see Figure 3). As a general finding, we note that RCR is still lower than the world standard for most countries in most of the fields. In more recent years, we can see few exceptions, particularly, Argentina and Mexico in clinical medicine (CL1), Chile mainly in the space sciences and mathematics as well as Colombia in clinical medicine and biology (less in engineering and no longer in physics).

In the case of Brazil, we observe a trend towards increasing RCR in some of the fields, notably in biology, agriculture and clinical medicine. Nevertheless, such efforts were not sufficient to reach the world's reference standard.
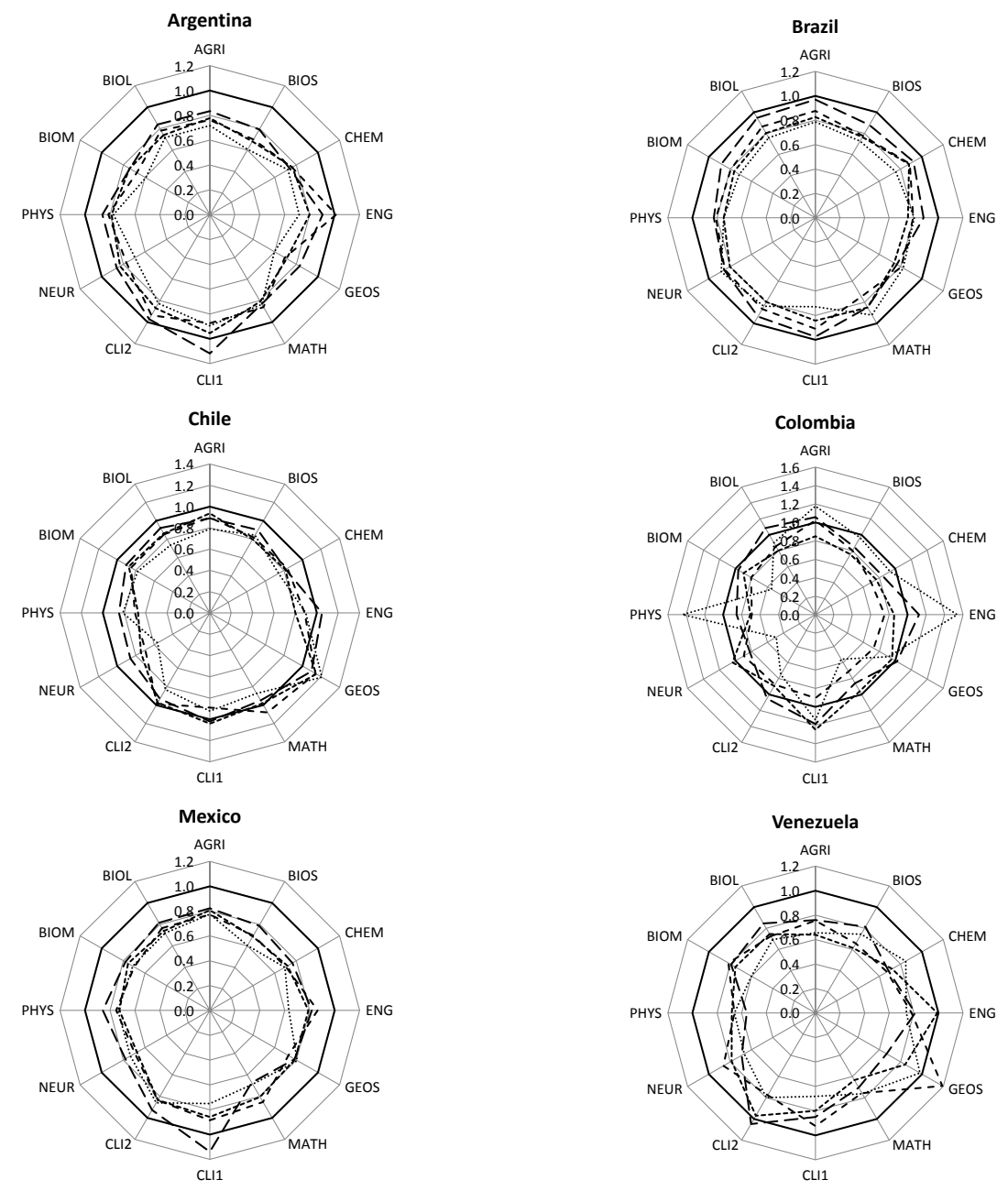

........ 1991-1995 -----1997-2001 - - 2002-2005 - 2006-2009 _-Standard

Figure 3. Evolution of Relative Citation Rate (RCR) of the most prolific Latin American countries. [Data sourced from Thomson Reuters Web of Science]

Legend: AGR = Agriculture \& Environment, Biology, BIOS = Biosciences, BIOM = Biomedical research, CLI1 $=$ Clinical \& Experimental Medicine I, CLI2= Clinical \& Experimental Medicine II, NEUR= Neuroscience \& Behaviour, CHEM= Chemistry, PHYS= Physics, GEOS= Geosciences \& Space Sciences, ENG= Engineering, $\mathrm{MATH}=$ Mathematics 


\section{INTERNATIONAL COLLABORATION IN LATIN AMERICAN SCIENCE}

Collaboration is a one of the characteristics of modern science in the age of globalization. The image of a scientist working alone has changed a lot, notably after the $19^{\text {th }}$ century, when science was embraced by universities gaining social recognition as a new social activity, and entered the era of 'big science' with massive funding and extensive team work (Price, 1963). From then on, the dynamics of the scientific work has encompassed different aspects of collaboration. Nowadays advancement of science has become unimaginable without any level of co-operation. The reasons for collaboration include, among others, infra-scientific factors, access to expertise, equipment, resources and funding, saving costs, meeting the challenges of increasing interdisciplinarity and globalization, but also geo-political, economic or cultural interests are pointed out to contribute to the establishment of international collaboration (Beaver and Rosen, 1978, 1979a,b; Luukkonen et al., 1992; Katz and Martin, 1997; Beaver, 2001).

One method to measure collaboration in science is based on coauthorship links. Using this variable, which is only a proxy, but at the macrolevel an acceptable mirror of collaboration (cf, Glänzel and Schubert, 2004), many scientometric studies have found that publications co-authored by researchers of different countries have strongly increased in the last decades (Leclerc and Gagne, 1994; Glänzel, 2001; Glänzel and Schubert, 2004). In our previous paper, we have also investigated this issue and have found that with the exception of Brazil, the share of internationally co-authored publications increased notably in the region under study, that is, in Argentina, Chile, Mexico and Venezuela.

Extending the study to the more recent period 2007-2011, we can observe that the share of international co-publications from Argentina, Chile and Venezuela increased even more, Mexico stagnated, while Brazil and Colombia reduced their share of internationally co-authored publications. Brazilian science and scientists have passed have passed through changeful 
times till in the 1990's the Brazilian science system became stable and international collaboration was not more a vital requirement. For some of the neighbor countries, however, international collaboration might still be a key mechanism for keeping their scientific activities alive (see also Braun and Glänzel, 1996).

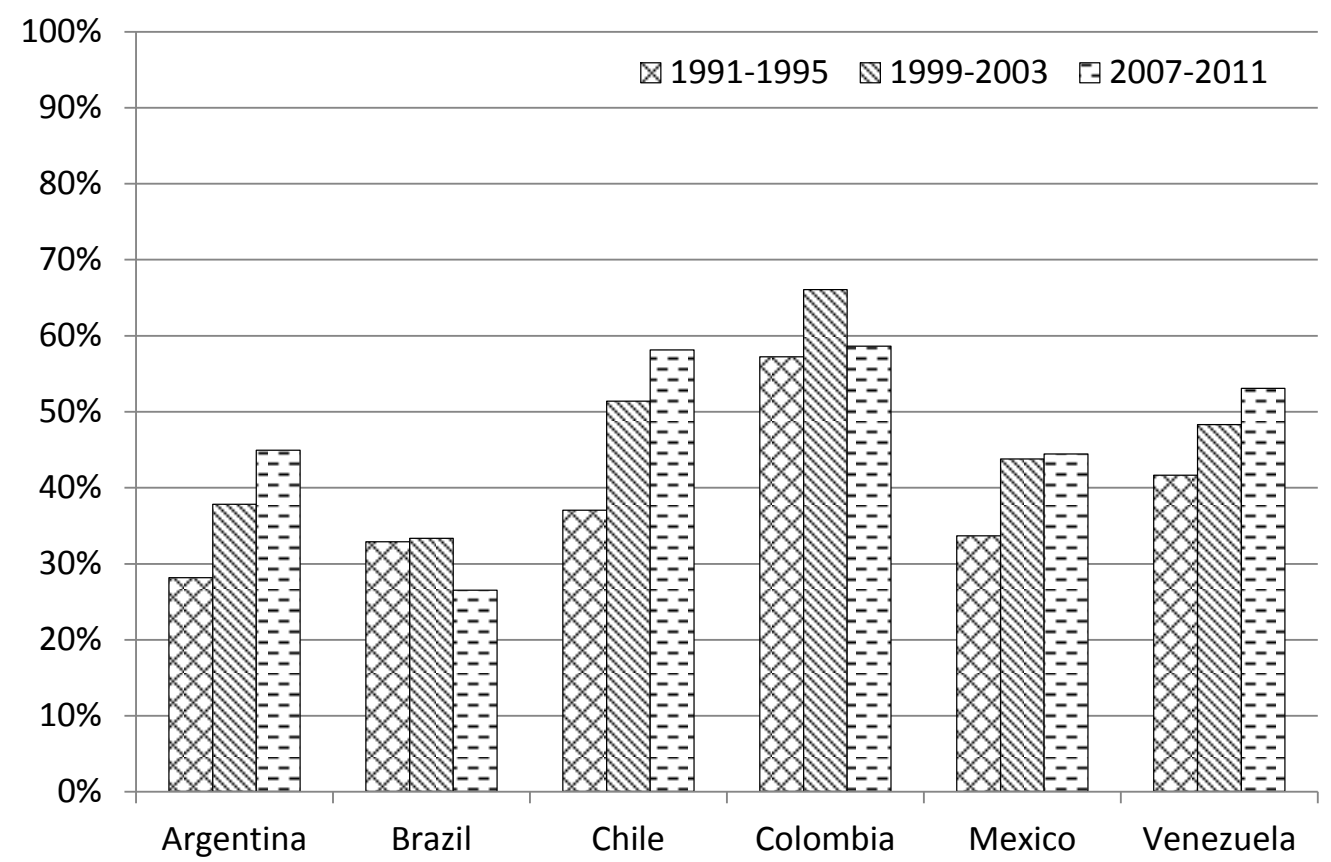

Figure 4: Share of international co-publications in some Latin American countries, 19911995, 1999-2003 and 2007-2011.

[Data sourced from Thomson Reuters Web of Science]

\section{CONCLUSIONS}

The present paper aims at investigating whether the recently growing number of Brazilian periodicals covered by the Web of Science contributed to changes in the country's publication output and research performance as compared with the patterns presented in a previous study. The data presented here clearly show that Brazilian relative share to the world total number of publications has considerably increased. In a period of 20 years, the country moved from the $23^{\text {rd }}$ to the $13^{\text {th }}$ position in the world ranking. Nevertheless, this striking increase of Brazil's weight in the global scientific landscape is not paralleled by a better research performance of the country in more recent years 
as reflected by both the Activity Index (AI) and the Relative Citation Rate (RCR). We brought furthermore some evidence that corroborate our previous study in which we affirm that Brazil is by far the region's leadership.

Brazil's central role in publication output is, however, contrasted by its modest citation impact. Considering the RCR as a relative index of world visibility, our data indicate that Brazilian visibility is low in all fields during the whole period under study. In more recent years, we note a discrete trend in increasing visibility, that is, an increase of RCR values. This trend may be explained by the national journals included in the database: the larger the number of Brazilian number, the larger the chances to find citations to Brazilian papers. This dynamics might have positive effect on the Brazilian relative citation impact.

\section{REFERENCES}

Beaver, D. deB., Rosen, R. (1978), Studies in scientific collaboration. Part 1. The professional origins of scientific co-authorship. Scientometrics, 1(1), 65-84.

Beaver, D. deB., Rosen, R. (1979a), Studies in scientific collaboration. Part 2. Scientific co-authorship, research productivity and visibility in the French elite. Scientometrics, 1(2), 133-149.

Beaver, D. deB., Rosen, R. (1979b), Studies in scientific collaboration. Part 3. Professionalization and the natural-history of modern scientific co-authorship. Scientometrics, 1(3), 231-245

Beaver, D. deB. (2001). Reflections on scientific collaborations (and its study): Past, present and prospective. Scientometrics, 52(3), 365-377.

Braun, T., Glänzel, W. (1996), International collaboration: Will it be keeping alive east European research? Scientometrics, 36(2), 247-254.

Braun, T., Glänzel, W., Schubert, A. (1985), Scientometric Indicators. A 32 Country Comparison of Publication Productivity and Citation Impact. World Scientific, Singapore - Philadelphia, 1985, 424 pp.

Frame, J.D. (1977), Mainstream research in Latin America and the Caribbean. Interciencia, 2, 143-148 
Glänzel, W. (2001), National characteristics in international scientific coauthorship relations. Scientometrics, 51(1), 69-115.

Glänzel, W., Schubert, A. (2003), A new classification scheme of science fields and subfields designed for bibliometric evaluation purposes. Scientometrics, 56(3), 357-367.

Glänzel, W., Schubert, A. (2004), Analyzing scientific networks through coauthorship, In: H.F.M. Moed, W. Glänzel, U. Schmoch (Eds), Handbook of Quantitative Science and Technology Research. The Use of Publication and Patent Statistics in Studies on S\&T Systems. Kluwer Academic Publishers, Dordrecht, The Netherlands, 257-276.

Glänzel, W., Leta, J. Thijs, B. (2006). Science in Brazil. Part 1: a macro-level comparative study. Scientometrics, 67(1) , 67-86.

Glänzel, W., Debackere, K., Meyer, M. (2008), 'Triad' or 'Tetrad'? On global changes in a dynamic world. Scientometrics, 74(1), 71-88.

Huggett, S. (2012), The rise of Latin American science. Research Trends 31, 15-

18. Available at: http://www.researchtrends.com/wpcontent/uploads/2012/11/Research_Trends_Issue_31.pdf

Katz, J.S., Martin, B.R. (1997). What is research collaboration? Research Policy, $26,1-18$.

Leclerc, M., Gagne, J. (1994) International scientific cooperation - the continentalization of science. Scientometrics, 31(3), 253-263.

Leta, J., Glänzel, W., Thijs, B. (2006), Science in Brazil. Part 2: Sectorial and institutional research profile. Scientometrics, 61(1), 87-105.

Leta, J. (2011). Growth of Brazilian Science: a real internalization or a matter of databases' coverage? In: E. Noyons, P. Ngulube, J. Leta (Eds), Proceedings of ISSI 2011 - The $13^{\text {th }}$ International Conference on Scientometrics and Informetrics, Durban, South Africa, Vol. 1, 392-397.

Luukkonen, T., Persson, O., Silvertsen G. (1992), Understanding patterns of international scientific collaboration. Science, Technology \& Human Values, 17(1), 101-126.

Price, D. deSolla (1963). Little Science, Big Science. Columbia Univ. Press, New York. 
Regalado A. (2010) Brazilian Science: Riding a Gusher. Science, 330(6009), 1306-1312.

REIST-2 (1997). The European Report on Science and Technology Indicators 1997. EUR 17639. Brussels, European Commission.

Schlemmer, B., Glänzel, W. (2008), R\&D Profiles of Cuba and other countries of the Carribbeans in the 1990's and the New Millennium. INFO 2008 - Knowledge Society: New Spaces to Build It. Havana, Cuba. ISBN: 959-234-040-4. 